\title{
Template-Free Synthesis of Aligned Polyaniline Nanorods/Tubes and Copper/Copper Hydroxide Nanowires for Application as Fillers in Polymer Nanocomposites
}

\author{
Jasper Chiguma, Wayne E. Jones Jr.* \\ Department of Chemistry and Materials Science and Engineering, Binghamton University, Binghamton, NY, USA \\ Email: bj95108@bingham ton.edu, *wjones@binghamton.edu
}

\begin{abstract}
How to cite this paper: Chiguma, J. and Jones Jr., W.E. (2018) Template-Free Synthesis of Aligned Polyaniline Nanorods/Tubes and Copper/Copper Hydroxide Nanowires for Application as Fillers in Polymer Nanocomposites. Advances in Materials Physics and Chemistry, 8, 71-88.

https://doi.org/10.4236/ampc.2018.81006
\end{abstract}

Received: December 14, 2017

Accepted: January 28, 2018

Published: January 31, 2018

Copyright $\odot 2018$ by authors and Scientific Research Publishing Inc. This work is licensed under the Creative Commons Attribution International License (CC BY 4.0).

http://creativecommons.org/licenses/by/4.0/

\begin{abstract}
Aligned polyaniline nanorods were synthesized in the presence of salicylic acid. Nanorods and nanotubes were also formed in the presence of camphorsulfonic acid (CSA) and para-toluenesulfonic acid (pTSA). Electrical conductivity measurements showed that the aligned nanorods had better electrical conductivity than the non-aligned nanostructures. Nanospheres were also observed in some cases. The formation of elongated nanostructures or spheres depended on the aniline monomer to surfactant molar ratio. This method in which nanostructures are formed using soft templates is often referred to as the template-free approach. Our success motivated us to explore the feasibility of obtaining similar metallic nanostructures without the use of a template. We successfully synthesized copper and copper hydroxide nanowires. While the copper nanowires formed as a mesh, the copper hydroxide nanowires formed as winding bundles. Upon switching the order in which the reactants were added, copper hydroxide nanoribbons were formed instead of bundles. Characterization of these nanostructures was done using Scanning Electron Microscopy (SEM), Atomic Force Microscopy (AFM), Transmission Electron Microscopy (TEM), Fourier Transform Infrared Spectroscopy (FTIR) and the Four-point probe to measure electrical conductivity. Both metallic and organic nanowires that are fabricated by template-free methods are potential candidates for use as fillers in polymer nanocomposites. Polymer nanocomposites are found to be used in many advanced modern applications such as thermal interface materials in electronic devices which continue to be miniaturized, aerospace engineering where lightweight and robustness are important, sensors, medicine and catalytic activity.
\end{abstract}




\section{Keywords}

Template-Free, Nanotubes/Rods, Surfactant, Molar Ratio, Polyaniline

\section{Introduction}

The oxidative, in-situ polymerization of polyaniline has been well established in the literature and leads to controlled thin film materials. Recently many groups have been exploring the in-situ generation of nanostructures from templates. We have been exploring new approaches to produce aligned polyaniline nanostructures during a template free synthesis. One promising method that has been reported in literature is the formation of polyaniline nanotubes without the use of a template and is referred to as the template-free approach [1] [2]. The morphology and diameter of the nanostructures depend on a number of factors. Among them are the structures of the monomer, dopant and oxidant. Equally influential in the formation of these nanostructures are the concentrations of the reactants, the molar ratio of the dopant and oxidant to monomer as well as the reaction temperature, time and stirring [3] [4].

Surfactants are a common soft template because they easily form thermodynamically stable and controllable nanometer-scale micelles in solution or at interfaces [5] [6]. The equilibrium size and shape of surfactant aggregates are controlled by the formula: $V_{o} / \alpha l_{o}$, where $V_{o}$ and $I_{o}$ are the volume and length of surfactant tail within the hydrophobic core of the aggregate and $\alpha$ is the effective area occupied by each surfactant head group at the surface of the aggregate. The favored aggregate morphology of the surfactant in solution, such as spherical, cylindrical, or a flat bi-layer, is formed depending on the value of $\alpha$. On the basis of the characteristics of surfactants, it has been proposed that the micelles formed by dopant, dopant/monomer salt or supermolecules, and even by the monomer itself might serve as the soft template in the self-assembly of template-free synthesis of nanostructures [7].

Nanotubes and nanorods of polyaniline were synthesized in the presence of salicylic acid, camphorsulfonic acid and p-toluenesulfonic acid. Generally, the dopants used for doping polyaniline (PANi) are small organic or inorganic molecules. The disadvantage with the small acid dopants is their tendency to evaporate at room temperature [8] [9]. Consequently, the conductivity of the acid-doped PANi diminishes. The problem associated with the loss of the acid dopants can be solved by using non-volatile acid dopants such as salicylic acid, camphorsulfonic acid and p-toluenesulfonic acid. Polyaniline is one of the best known conducting polymers such as polypyrrole and poly (3, 4-ethyleedioxythiophene) (PEDOT) [10] [11]. Conducting polymers as molecular wires have recently received great attention because of their long conjugation length, metallic conductivity and promising applications in nanodevices [12] [13]. Polyaniline (PANI) is a polymer that attracts research scientists due to its simple preparation, good thermal 
and environmental stability, structure versatility, and potential applications as electrical and optical materials [14] [15] [16] [17].

Here we report the template-free synthesis of aligned polyaniline nanowires in the presence of salicylic acid. In similar but related experiments camphorsulfonic acid and para-toluenesulfonic acid were used as surfactants during the polymerization of aniline and nanotubes and nanowires were obtained. To show that the formation of nanowires without the use of a template is not limited to conducting polymers, copper and copper(II) hydroxide nanowires were also synthesized without the use of a template. These were characterized by Scanning Electron Microscopy (SEM), Transmission Electron Microscopy (TEM), Atomic Force Microscopy (AFM), Fourier Transform Infrared Spectroscopy (FTIR) and Four-point probe.

\section{Experimental}

\subsection{Materials}

Aniline monomer, salicylic acid, camphorsulfonic acid, para-toluenesulfonic acid, potassium hydroxide, ammonium persulfate, acetone, copper(II) sulfate, sodium hydroxide, copper(II) nitrate and ethylenediamine were purchased from Aldrich and used as received except for aniline which was distilled before use.

\subsection{Polyaniline Synthesis}

For the synthesis of polyaniline nanostructures in the presence of salicylic acid, $0.4 \mathrm{~g}$ of aniline (ANI) was reacted with varying amounts of salicylic acid (SA) to achieve different [SA]/[ANI] molar ratios. Different [SA]/[ANI] combinations were used such that the ratio could be maintained as 1 and then varied to 0.5 and 1.2. The following concentration ratios were used: $0.1 / 0.2,0.2 / 0.2,0.24 / 0.2,0.1 / 0.1$, $0.15 / 0.15,0.2 / 0.2$, and $0.225 / 0.225$. The aniline and salicylic acid were dissolved in $20 \mathrm{ml}$ of DI water by ultrasonic stirring for 1 hour. The solution was rapidly cooled to room temperature and a piece of glass was immersed into the solution in vertical position. After 30 minutes, $10 \mathrm{ml}$ of solution containing $0.9 \mathrm{~g}$ ammonium persulfate were added followed by 5 minutes of magnetic stirring. The vials were sealed and left still for $15 \mathrm{~h}$. The precipitate collected on glass was washed with DI water and left to dry at room temperature [18].

"Polyaniline nanorods" were also synthesized using a similar approach but in the presence of para-toluenesulfonic acid (pTSA). Firstly, the aniline concentration [ANI] was fixed at $0.20 \mathrm{~mol} / \mathrm{L}$ while varying the concentration of pTSA, in order to obtain [pTSA]/[ANI] ratios of $0.05,0.1,0.25,1 / 1,2 / 1$ and $5 / 1$. Alternatively, the molar ratio [pTSA]/[ANI] was fixed to $1 / 1$. The concentrations of aniline $[\mathrm{ANI}]$ was varied and the corresponding amounts of pTSA added to maintain the ratio $[\mathrm{pTSA}] /[\mathrm{ANI}]=1 / 1$. The $[\mathrm{ANI}]$ used were $0.08,0.12,0.20,0.40$, and $0.50 \mathrm{~mol} / \mathrm{L}$. The solution was heated in an oil bath to get a transparent solution of pTSA-ANI solution, after which it was cooled in an ice bath. A cooled solution of ammonium persulfate of concentration $0.2 \mathrm{~mol} / \mathrm{L}$ was added to the 
cooled pTSA-ANI solution. The mixture was left still in an ice bath for $15 \mathrm{~h}$. After filtering and washing with distilled water and acetone, the precipitate was allowed to dry at room temperature for $24 \mathrm{~h}$ [19].

"Polyaniline nanotubes" were synthesized by dissolving $2 \times 10^{-3} \mathrm{~mol}$ of aniline and $1 \times 10^{-3} \mathrm{~mol}$ of camphorsulfonic acid in $10 \mathrm{ml}$ of DI water, followed by cooling in an ice bath. A solution of ammonium persulfate was made by dissolving $2 \times 10^{-3} \mathrm{~mol}$ of ammonium persulfate in $5 \mathrm{ml}$ of DI water. After cooling in an ice bath, the ammonium persulfate solution was added to the aniline/ camphorsulfonic acid solution. The solution was left to react in an ice bath for 15 $\mathrm{h}[20]$.

\subsection{Copper(II) Hydroxide Nanowires $\left(\mathrm{Cu}(\mathrm{OH})_{2}\right)$}

Two two-step template-free methods were used to synthesize $\mathrm{Cu}(\mathrm{OH})_{2}$ nanowires. The $\mathrm{KOH} / \mathrm{NH}_{3}$ method consists of adding $0.8 \mathrm{ml}$ of $1 \mathrm{M} \mathrm{KOH}$ solution to $2 \mathrm{ml}$ of $0.1 \mathrm{M} \mathrm{CuSO}_{4}$ solution under stirring at room temperature. The addition of $\mathrm{KOH}$ to $\mathrm{CuSO}_{4}$ was followed by the addition of $0.3 \mathrm{ml}$ of ammonia solution $(29.6 \mathrm{wt} \%-0.897 \mathrm{M})$. After adding ammonia solution, the mixture was further stirred for 3 minutes. The mixture was kept static in a sealed vial for $12 \mathrm{~h}$. The precipitate was filtered off, washed thoroughly with DI water and left to dry for $12 \mathrm{~h}$. The second method was similar to the $\mathrm{KOH} / \mathrm{NH}_{3}$ method except that $\mathrm{KOH}$ was added after the addition of $\mathrm{NH}_{3}$ and therefore called the $\mathrm{NH}_{3} / \mathrm{KOH}$ method [21].

\subsection{Copper Nanowires}

The template-free synthesis of copper nanowires was achieved by adding to a glass vial, $20 \mathrm{ml}$ of $\mathrm{NaOH}(3.5 \mathrm{M})$ and $0.5 \mathrm{~mL}$ of $\mathrm{Cu}\left(\mathrm{NO}_{3}\right)_{2}(0.1 \mathrm{M})$ aqueous solutions. To the same vial, $0.05 \mathrm{ml}$ of $99 \mathrm{wt} \% \mathrm{EDA}$ and $0.02 \mathrm{ml}$ of $35 \mathrm{wt} \%$ were added sequentially, followed by thorough mixing. The vial was placed in a water bath and the bath temperature was fixed at $60^{\circ} \mathrm{C}$. The reactants were left in the water bath for 15 hours. The copper nanowires were washed and harvested by centrifugation. To prevent them from oxidation the nanowires were stored in water-hydrazine solution [22].

Characterization of these nanostructures was done using SEM (Hitachi Model S-570), AFM (Nanoscope IIIa), TEM (Hitachi Model H-7000), UV-vis (Hewlett Packard 8453A Diode Array Spectrophotometry), FTIR (FTS 40 Pro) and the Four-point probe (Keithley 220 programmable current source coupled with Keithley 182 Sensitive Digital Voltmeter) to measure conductivity.

\section{Results and Discussion}

\subsection{Polyaniline Nanowires and Nanotubes}

By using salicylic acid as the dopant and ammonium persulfate as the oxidant we achieved room temperature synthesis of aligned polyaniline nanofibers. Different nanostructures were observed for different molar ratios of salicylic acid and 
aniline (SA/ANI). The SEM images of the structures that were formed at each molar ratio are shown in Figure 1. At a molar ratio of 0.1/0.2, Figure 1(a), no fibers or well-defined structures were formed. However, at a ratio of 0.2/0.2, Figure 1(b) cylindrical structures started to form.

Clusters of nanofibers with well-defined orientation that are formed at a ratio of 0.24/0.2 are shown in Figures 1 (c)-(e). The morphology of the nanostructures at a ratio of $0.1 / 0.1$, Figure $1(\mathrm{f})$ and Figure $1(\mathrm{~g})$ is dominated by spheres. A transition from a nanosphere-dominated morphology at a ratio of $0.1 / 0.1$ to a mixture of nanospheres and nanofibers is observed at a ratio of $0.15 / 0.15$, Figure 1 (f) and $0.2 / 0.2$, Figure 1 (i). At a ratio of $0.225 / 0.225$, Figure $1(\mathrm{j})$ and Figure $1(\mathrm{k})$, well aligned nanofibers can be observed as was the case at a ratio of 0.24/0.2. The surface structures of some of the spheres that were obtained during the synthesis at a ratio of $0.225 / 0.225$ with aligned nanofibers emerging from their surface are shown in Figure 1(l) and Figure 1(m). The TEM images of the aligned nanofibers are shown in Figure 1(n) and Figure 1(o). It can be clearly seen that these fibers practically run parallel to each other.

To further examine the structure of these polyaniline structures, AFM topographic and amplitude images of the nanostructures at each SA/ANI ratio were also taken and are shown in Figure 2. The height images are shown in Figure 2(a) Figure 2(c) and Figure 2(e) while the corresponding amplitude images are shown in Figure 2(b), Figure 2(d) and Figure 2(f). The spheres that were observed by SEM can also be clearly seen in the images in Figures 2(a)-(d), a fiber strand can be seen in Figure 2(e) and Figure 2(f).

The morphologies and conductivity results of the nanofibers that were obtained at each SA/ANI ratio are summarized in Table 1 . The conductivities were calculated based on the films that were formed on the respective pieces of glass. The conductivities were calculated by first calculating the resistivity using the following formula:

$$
\rho=(\pi t / \ln 2)(V / I)
$$

where $\rho$ is the sheet resistivity, $\mathrm{t}$ is the film thickness, $V$ is the voltage and $I$ is the current. The inverse: $1 / \rho$ is the conductivity in $\mathrm{S} / \mathrm{cm}$. Film thickness was determined to be $206.89 \mathrm{~nm}$ using AFM in the Contact mode.

The conductivity values seem to reveal an interesting pattern whereby the SA/ANI ratio in which the morphology was predominantly composed of spheres has the lowest conductivity. In general where nanofiber structures were formed the electrical conductivities were found to be higher by 2 - 3 orders of magnitude than when spheres were formed.

The FTIR spectrum that was obtained for the nanofibers and nanotubes is shown in Figure 3. The bands at 1622, 1572, 1452, 1289 and $1166 \mathrm{~cm}^{-1}$ were found to be characteristic of PANI.

The three bands at 1622,1572 and $1452 \mathrm{~cm}^{-1}$ correspond to the $\mathrm{C}=\mathrm{C}$ stretching of the benzenoid and quinoid rings. The bands at 1166 and $1289 \mathrm{~cm}^{-1}$ correspond to the $\mathrm{C}-\mathrm{N}$ stretch and $\mathrm{C}-\mathrm{H}$ bend respectively. The band at 1512 $\mathrm{cm}^{-1}$ corresponds to $\mathrm{C}=\mathrm{N}$ stretching of quinoid ring [23] [24]. 

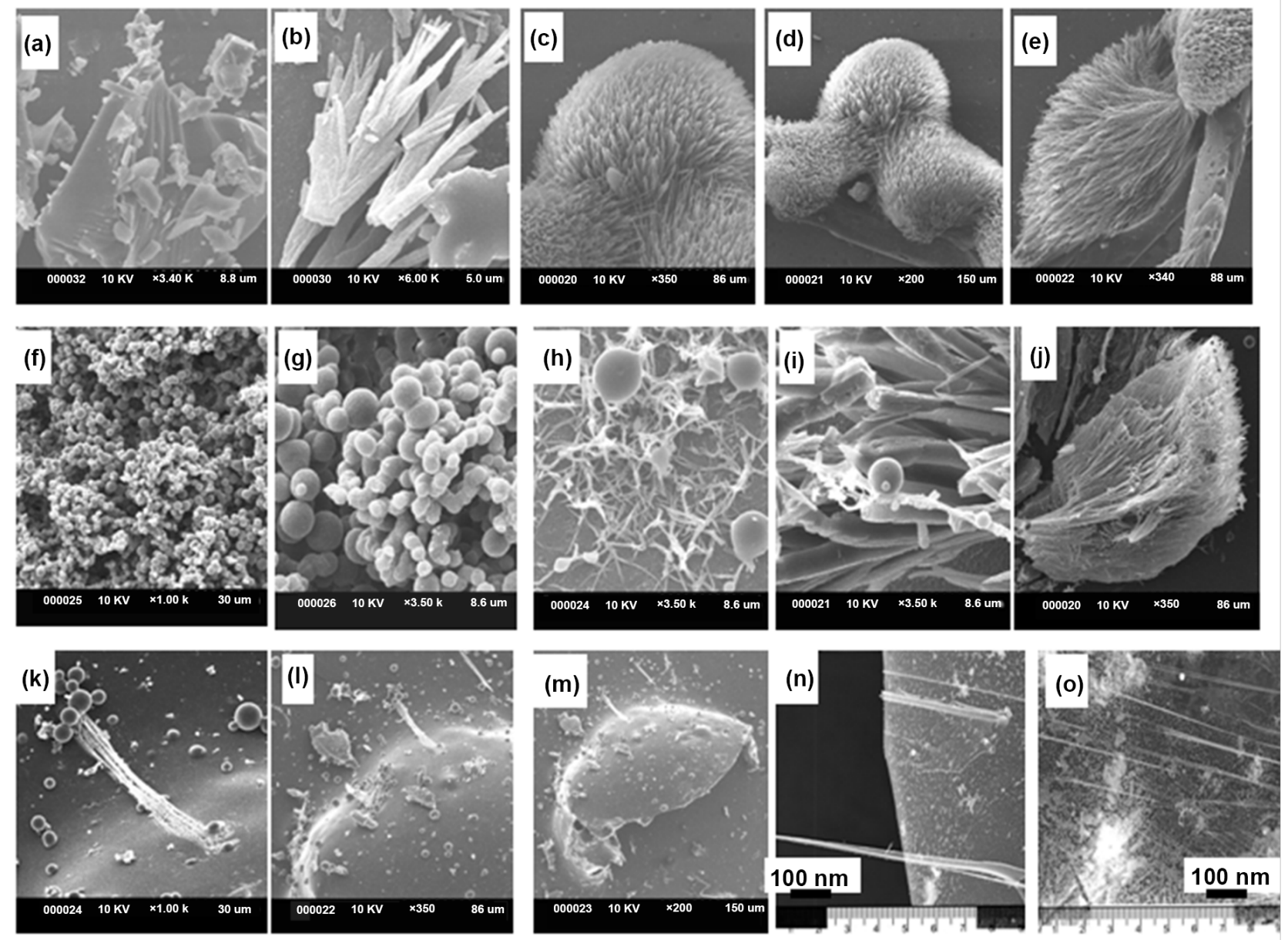

Figure 1. SEM images (a)-(m) and TEM images (n) and (o) of polyaniline nanostructures at different [SA]/[ANI] ratios.
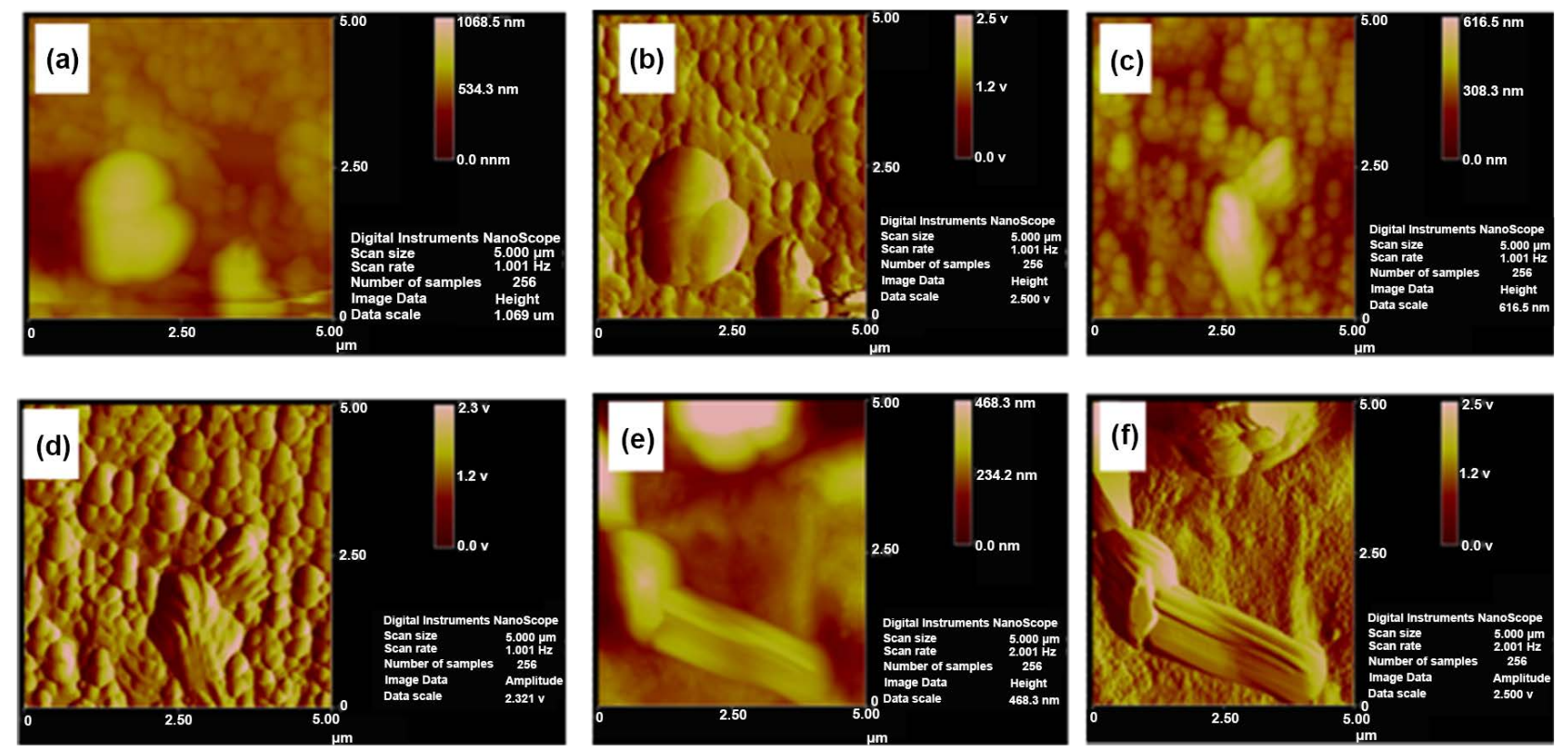

Figure 2. Tapping Mode AFM height images (a), (c), (e) and amplitude images (b), (d), (f) of polyaniline nanostructures at different $[\mathrm{SA}] /[\mathrm{ANI}]$ ratios. 


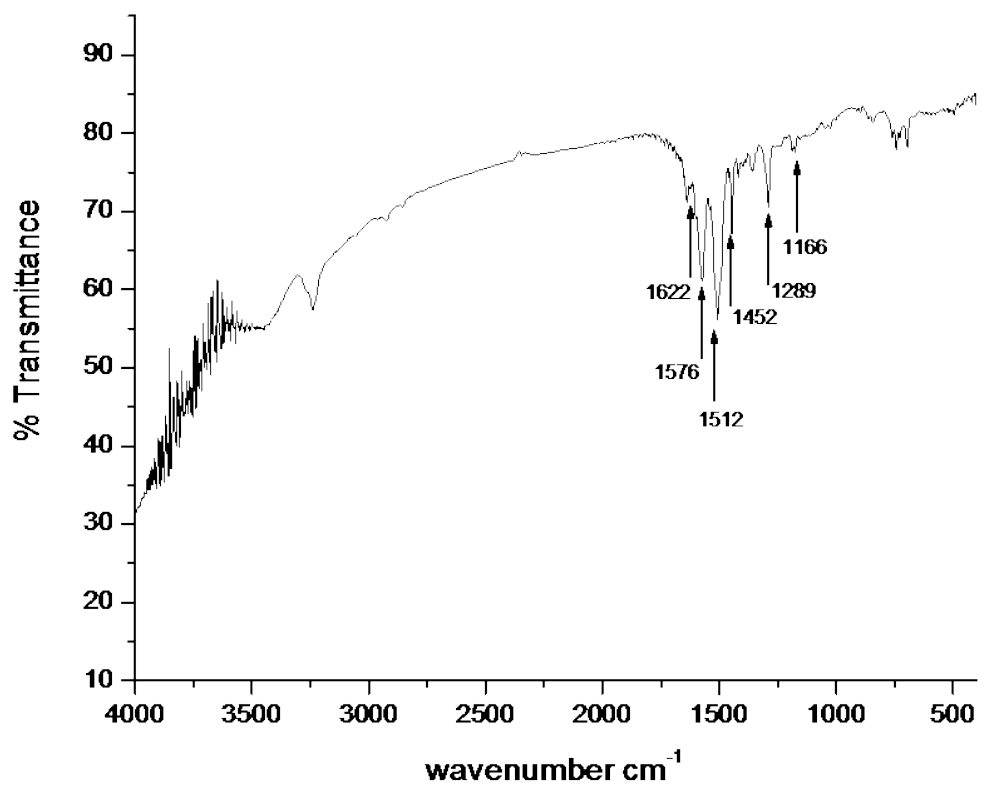

Figure 3. FTIR spectrum of polyaniline/salicylic acid nanostructures.

Table 1. Conductivity of polyaniline/salicylic acid at different molar ratios.

\begin{tabular}{ccccc}
\hline$[\mathrm{SA}]$ & {$[\mathrm{ANI}]$} & {$[\mathrm{SA}] /[\mathrm{ANI}]$} & Structure & Conductivity \\
\hline$(\mathrm{Mol} / \mathrm{L})$ & $(\mathrm{Mol} / \mathrm{L})$ & Ratio $(\mathrm{S} / \mathrm{cm})$ & & $1.10 \times 10^{-3}$ \\
0.10 & 0.20 & 0.50 & No fibers & $9.76 \times 10^{-3}$ \\
0.20 & 0.24 & 1.00 & Nonaligned & $1.46 \times 10^{-2}$ \\
0.24 & 0.20 & 1.20 & Aligned & $1.29 \times 10^{-4}$ \\
0.10 & 0.10 & 1.00 & Spheres & $3.34 \times 10^{-2}$ \\
0.15 & 0.15 & 1.00 & Crosslinked & $4.46 \times 10^{-2}$ \\
0.20 & 0.20 & 1.00 & Nonaligned & $3.65 \times 10^{-2}$ \\
0.225 & 0.225 & 1.00 & Aligned & 3 \\
\hline
\end{tabular}

The formation of nanostructures was also studied using camphorsulfonic acid, which unlike salicylic acid has a bicyclic structure and a sulfonic acid group [25]. Besides, camphorsulfonic acid is thermally stable with a decomposition temperature in the range of $193^{\circ} \mathrm{C}-195^{\circ} \mathrm{C}$. The SEM pictures that show the morphology of the nanostructures that were synthesized are shown in Figure 4(a) and Figure 4(b). These nanostructures were further analyzed using TEM. The TEM images shown in Figures 4 (c)-(f) revealed that the nanostructures were hollow. This showed that nanotubes had actually been synthesized. The conductivity for PANI/CSA at each molar ratio was obtained from compressed pellets. The conductivity values are shown in Table 2.

It can be seen from these conductivity data that as the molar ratio increases, the conductivity increases as well. However, the conductivity values are for these nanotubes do not increase as much as in nanowires. The low conductivity in polyaniline nanotubes might be attributed to the lack of sufficient crystallinity 

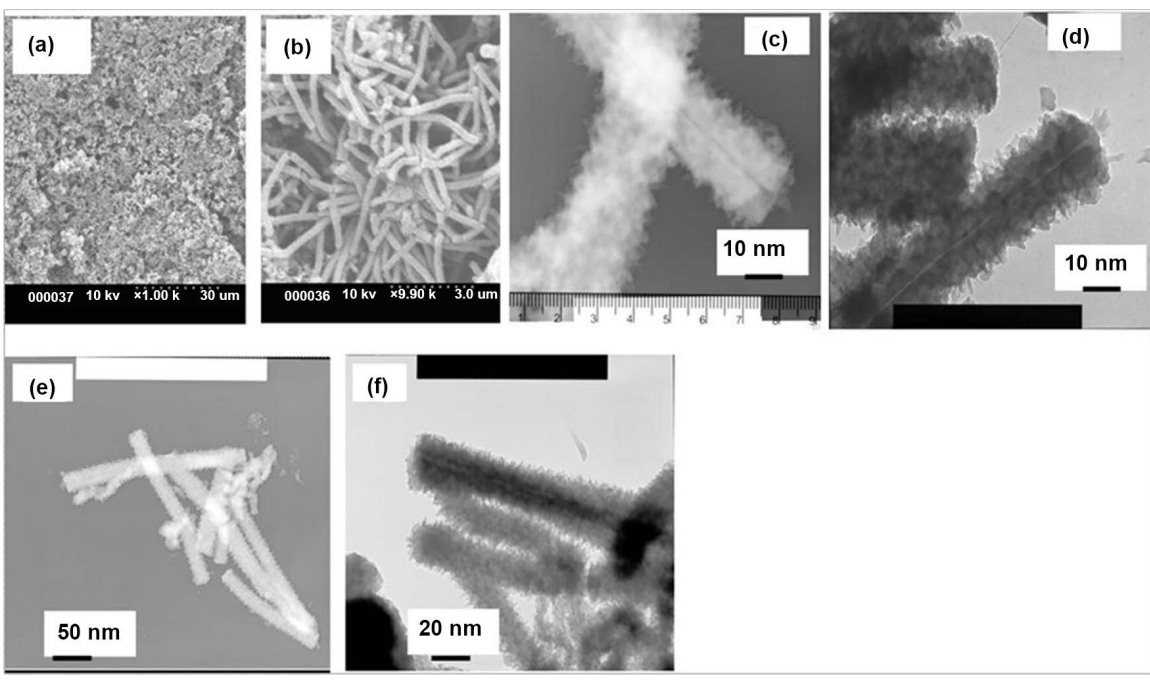

Figure 4. SEM images (a), (b) and TEM images (c), (d), (e) and (f) of polyaniline/camphorsulfonic acid nanostructures.

Table 2. Conductivity of polyaniline/salicylic acid at different molar ratios.

\begin{tabular}{ccclc}
\hline$[\mathrm{CSA}]$ & {$[\mathrm{ANI}]$} & {$[\mathrm{SA}] /[\mathrm{ANI}]$} & Structure & Conductivity \\
\hline$(\mathrm{Mol} / \mathrm{L})$ & $(\mathrm{Mol} / \mathrm{L})$ & Ratio$(\mathrm{S} / \mathrm{cm})$ & & \\
\hline $2 \times 10^{-3}$ & 0.20 & 0.50 & Nanotubes & $6.53 \times 10^{-5}$ \\
$2 \times 10^{-4}$ & 0.20 & 1.00 & Nanotubes & $7.44 \times 10^{-5}$ \\
$6 \times 10^{-4}$ & 0.20 & 1.20 & Nanotubes & $2.97 \times 10^{-4}$ \\
$2 \times 10^{-3}$ & 0.10 & 1.00 & Nanotubes & $1.82 \times 10^{-3}$ \\
$2 \times 10^{-3}$ & 0.15 & 1.00 & Nanotubes & $1.78 \times 10^{-3}$ \\
\hline
\end{tabular}

along the nanotube walls, whereas in nanowires the polyaniline might be more compact and crystalline which promotes electrical conductivity.

A plot of these conductivity data as a function of CSA/ANI ratio are shown in Figure 5. These conductivity data are comparable to the ones that are reported in literature. The FTIR spectrum that was obtained for polyaniline synthesized in the presence of CSA is shown in Figure 6.

The following band assignments can be made: 1576 and $1497 \mathrm{~cm}^{-1}(\mathrm{C}=\mathrm{C}$ stretching deformation of quinoid and benzenoid rings), $1304 \mathrm{~cm}^{-1}$ (C-N stretching of secondary aromatic amine), $1136 \mathrm{~cm}^{-1}$ (aromatic $\mathrm{C}-\mathrm{H}$ in-plane bending), $826 \mathrm{~cm}^{-1}$ (out-of-plane deformation of $\mathrm{C}-\mathrm{H}$ in the 1, 4-disubstituted benzene ring), $509 \mathrm{~cm}^{-1}$ (-SO $\mathrm{S}_{3} \mathrm{H}$ group) [26]. The presence of the $509 \mathrm{~cm}^{-1}$ band indicates the presence of D-CSA as a dopant in PANI [27].

Nanotubes were also obtained when pTSA was used as a dopant. The SEM images in Figure 7 show the morphology of the structures that were obtained at each pTSA/ANI molar ratio. Analysis of the nanostructures using TEM revealed that we had successfully synthesized nanotubes. The TEM images show uniform openings running through the center of the tubes. 


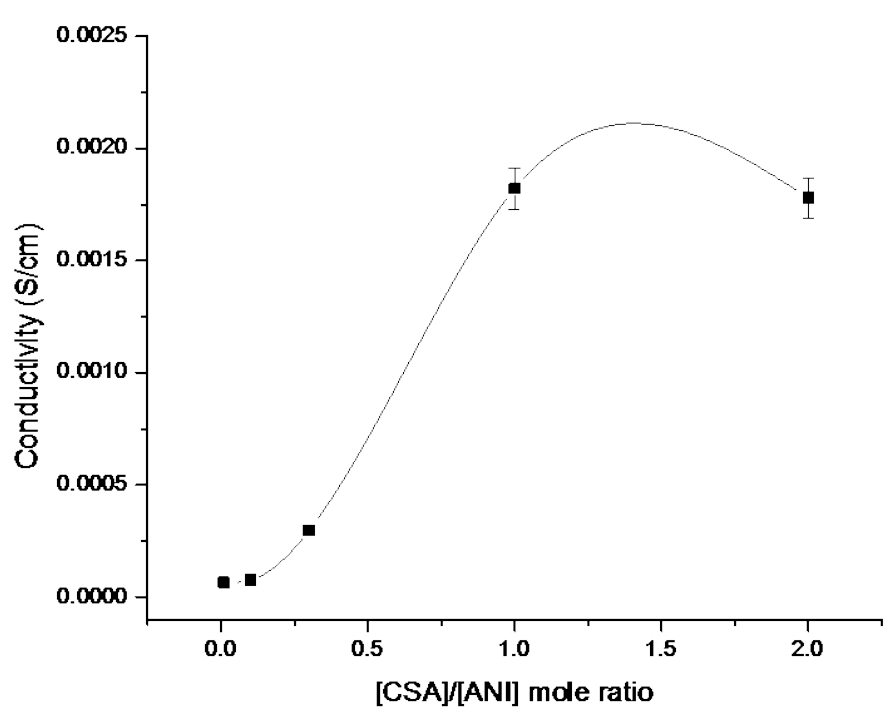

Figure 5. Variation of polyaniline/camphorsulfonic acid conductivity as a function of molar ratio.

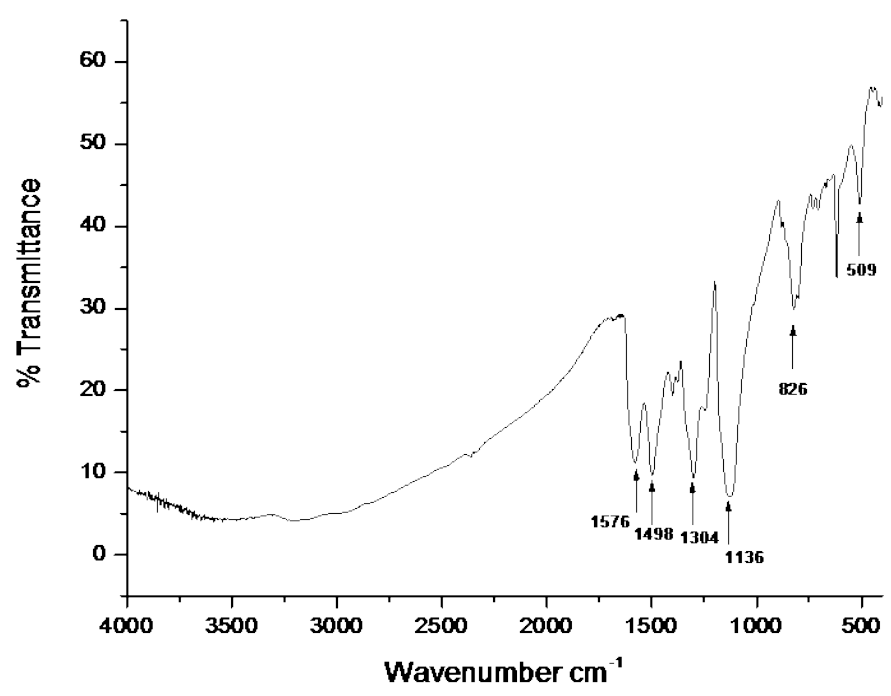

Figure 6. FTIR spectrum of polyaniline/camphorsulfonic acid nanostructures.

Nanotubes were obtained at the pTSA/ANI molar ratios of $0.05 / 1,0.1 / 1$ and $0.25 / 1$. The conductivity measurements that were obtained from compressed pellets at each pTSA/ANI ratio are summarized in Table 3. It can be seen from the plot in Figure 8 that conductivity increased with increasing molar ratio. However at higher molar ratio no nanotubes or nanorods were formed.

The IR spectrum that was obtained for pTSA doped polyaniline is shown in Figure 9. Bands at 1576 and $1491 \mathrm{~cm}^{-1}$ are assigned to the $\mathrm{C}=\mathrm{C}$ stretching deformation of quinoid and bezonoid rings, respectively. The peak at $1304 \mathrm{~cm}^{-1}$ corresponds to the $\mathrm{C}-\mathrm{N}$ stretching of the secondary amine. The peak at 1119 $\mathrm{cm}^{-1}$ can be assigned to the aromatic $\mathrm{C}-\mathrm{H}$ in-plane bending vibration mode of $\mathrm{N}=\mathrm{Q}=\mathrm{N}$, where $\mathrm{Q}=\mathrm{N}+\mathrm{H}-\mathrm{B}$, and $\mathrm{B}-\mathrm{N}+\mathrm{H}-\mathrm{B}$, which is formed during protonation. 

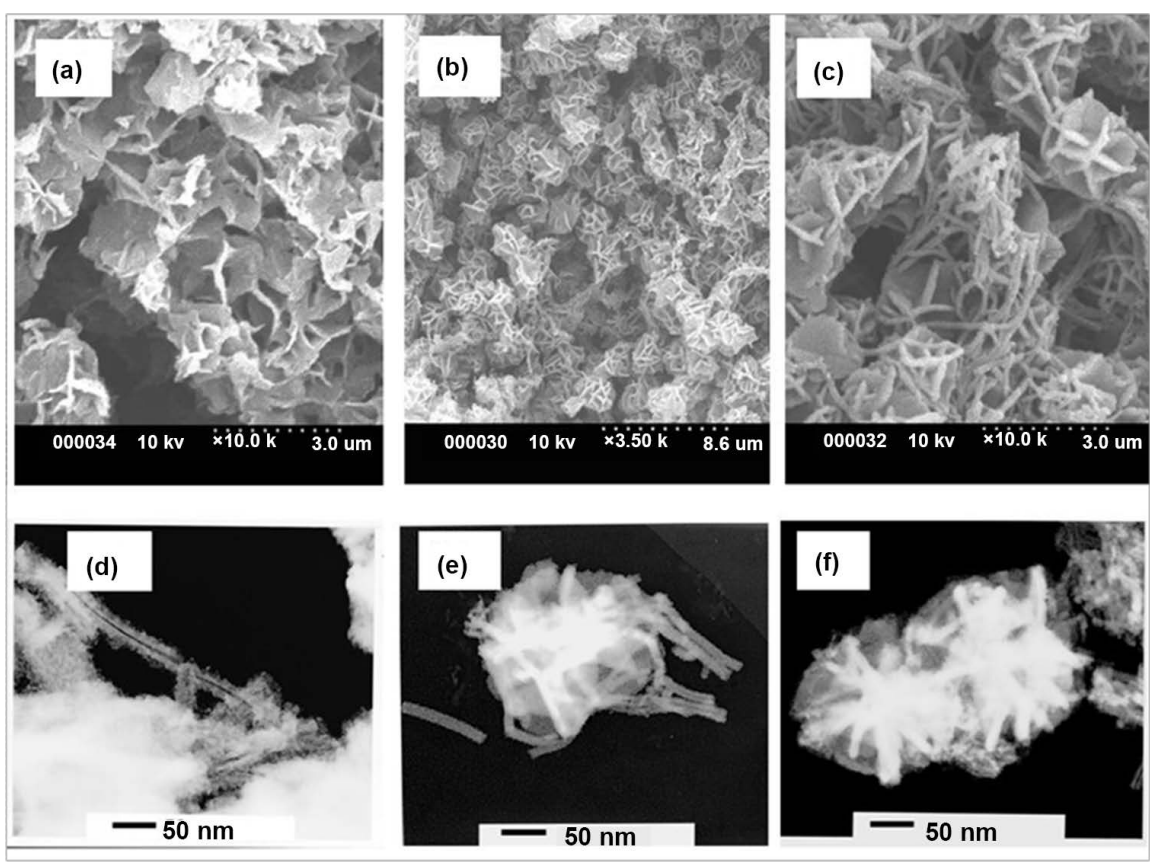

Figure 7. SEM images (a)-(c) and TEM images (d)-(f) of polyaniline/para-toluenesulfonic acid at different pTSA/ANI molar ratios.

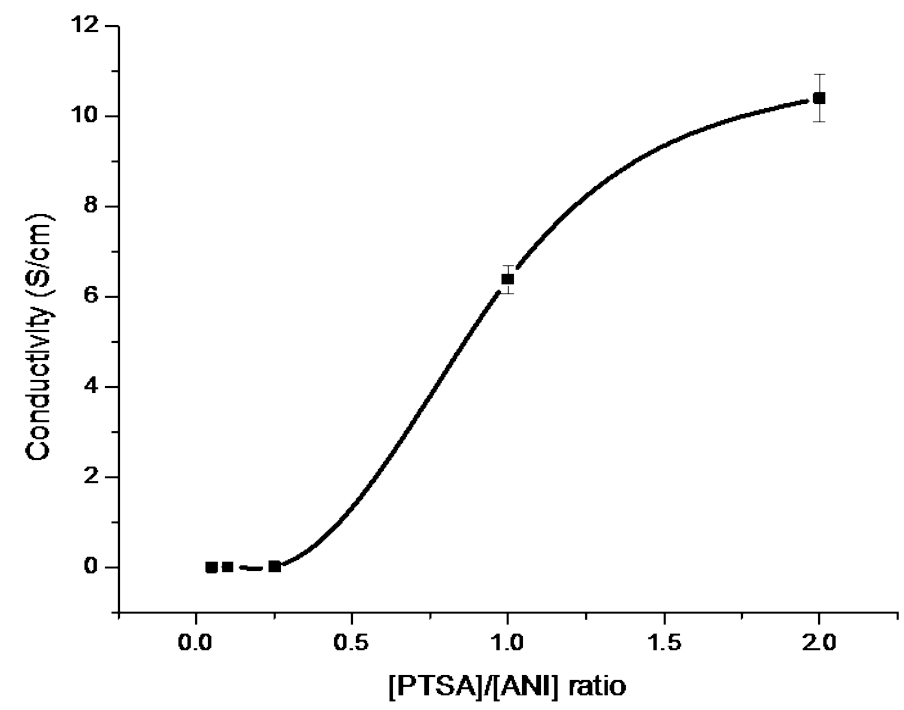

Figure 8. Variation of electrical conductivity of polyaniline/para-toluenesulfonic acid nanotubes/nanorods with molar ratio.

The band at $817 \mathrm{~cm}^{-1}$ is related to the out-of-plane deformation of $\mathrm{C}-\mathrm{H}$ in the 1, 4-disubstituted benzene ring, and the peak at $509 \mathrm{~cm}^{-1}$ is related to the aromatic ring deformation of $\mathrm{C}-\mathrm{H}$. The bands at 1034 and $686 \mathrm{~cm}^{-1}$ correspond to $-\mathrm{SO}_{3} \mathrm{H}$ showing that PANI was doped with TSA [28] [29].

\subsection{Copper Nanowires}

The formation of nanorods by self-assembly is not limited to polyaniline. It seems to be a natural phenomenon that occurs in other materials as well. The 
Table 3. Conductivity measurements of polyaniline/para-toluenesulfonic acid nanotubes/ nanorods.

\begin{tabular}{ccccc}
\hline$[\mathrm{pTSA}]$ & {$[\mathrm{ANI}]$} & {$[\mathrm{pTSA}] /[\mathrm{ANI}]$} & Structure & Conductivity \\
\hline$(\mathrm{Mol} / \mathrm{L})$ & $(\mathrm{Mol} / \mathrm{L})$ & Ratio & & $(\mathrm{S} / \mathrm{cm})$ \\
\hline 0.01 & 0.20 & $0.05 / 1$ & Nanotubes & $1.10 \times 10^{-4}$ \\
0.01 & 0.20 & $1.00 / 1$ & Nanotubes & $9.76 \times 10^{-5}$ \\
0.05 & 0.20 & $1.25 / 1$ & Nanotubes & $146 \times 10^{-2}$ \\
0.20 & 0.20 & $1.00 / 1 \mathrm{No}$ & Nanotubes & 6.38 \\
0.40 & 0.20 & $2.00 / 1 \mathrm{No}$ & Nanotubes & 10.42 \\
\hline
\end{tabular}

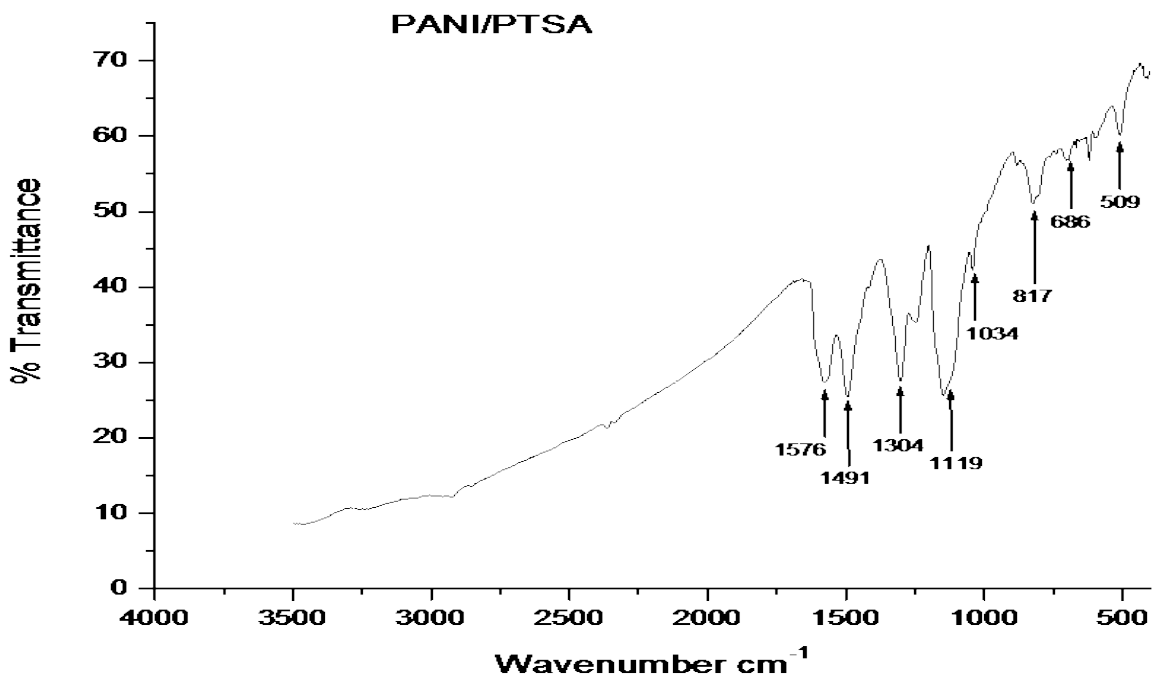

Figure 9. FTIR of polyaniline/para-toluenesulfonic acid nanotubes/nanorods.

SEM images of copper nanorods that were synthesized without the use of a template are shown in Figures 10(a)-(d) while Figure 10(e) shows the TEM image of the nanowires.

It can be seen that the nanorods are long with a smooth morphology. However, it can be seen that the ends of the copper nanowires consist of nods or spherical structures. This may suggest that the formation of copper nanowires starts with the formation of spherical structures. The following equation forms the basis of the formation of the metallic copper:

$$
2 \mathrm{Cu}^{2+}+\mathrm{N}_{2} \mathrm{H}_{4}+4 \mathrm{OH}^{-} \rightarrow 2 \mathrm{Cu}+\mathrm{N}_{2}+4 \mathrm{H}_{2} \mathrm{O}
$$

Even more interesting is the self-assembly of copper(II) hydroxide in which the simple switching of the order in which the reactants are added switches the structure between nanorods and nanoribbons. The formation of long winding bundles copper(II) hydroxide nanorods proceeds according to the following equation:

\section{$\mathrm{NH}_{3} / \mathrm{KOH}$ Route}

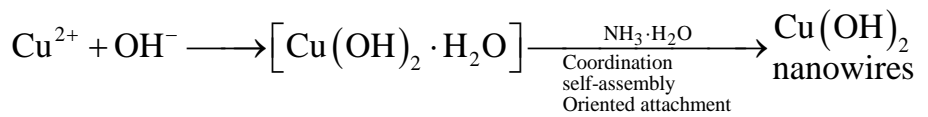



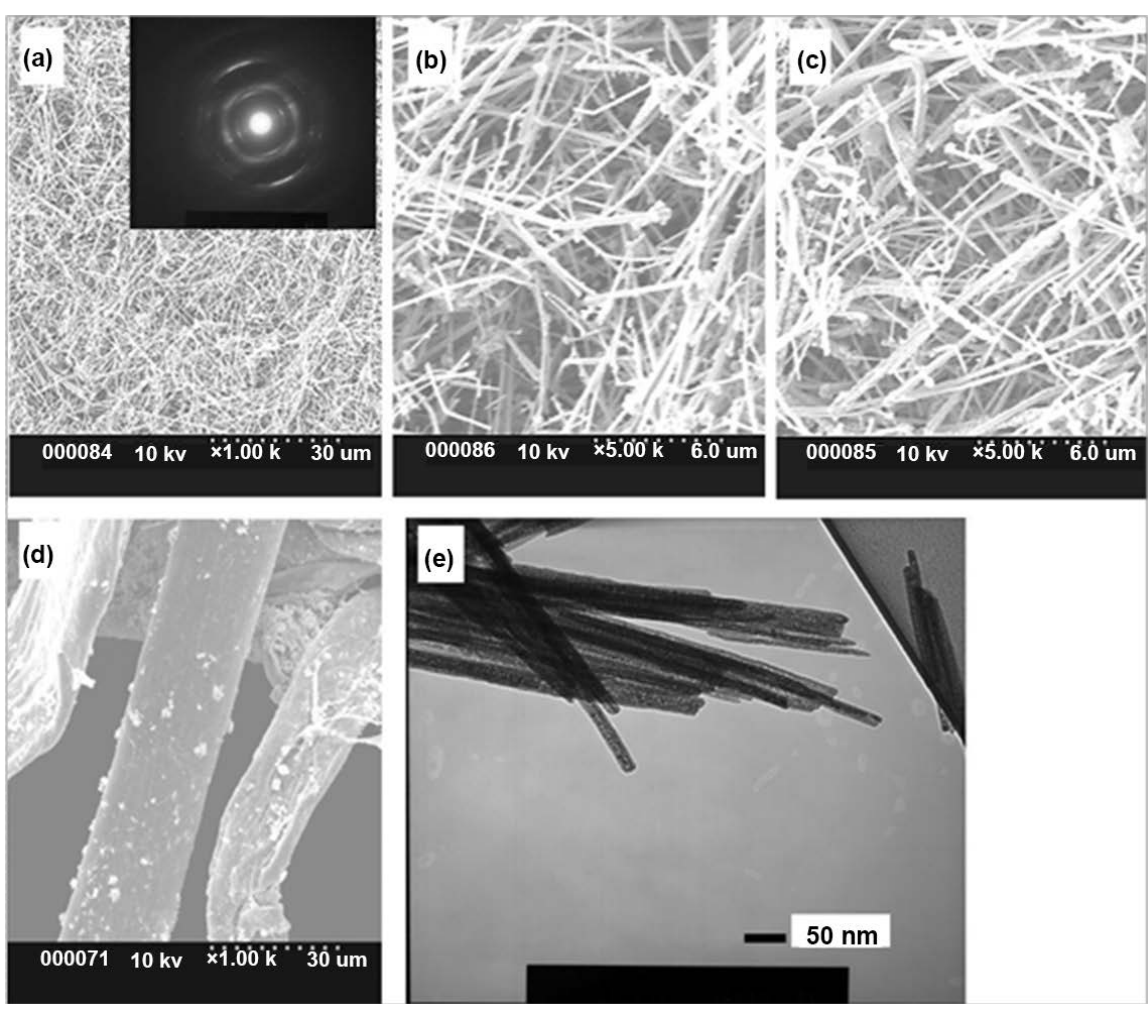

Figure 10. SEM images (a), (b), (c) and TEM image (e), of copper nanowires. The insert is the electron diffraction image of the copper nanowires.

The SEM images of the copper(II) hydroxide nanorods that were synthesized in the absence of any surfactant are shown in Figure 11(a) and Figure 11(b). It can be seen that the nanorods form long bundles of copper(II) hydroxide.

The equation below represents the formation of copper(II) hydroxide nanoribbons upon switching the order in which the reactants are added.

\section{$\mathrm{KOH} / \mathrm{NH}_{3}$ route}

$$
\mathrm{Cu}^{2+}+\mathrm{NH}_{3} \cdot \mathrm{H}_{2} \mathrm{O} \longrightarrow\left[\mathrm{Cu}\left(\mathrm{NH}_{3}\right)_{\mathrm{n}}\right]^{2+} \underset{\substack{\text { Coordination } \\ \text { self-assembly }}}{\stackrel{\mathrm{OH}^{-}}{\longrightarrow}} \underset{\text { nunoribbons }}{\mathrm{Cu}(\mathrm{OH})_{2}}
$$

The copper(II) hydroxide nanoribbons that are formed when the order in which the reactants are added is reversed are shown in Figures 12(a)-(e).

Different growth mechanisms for copper nanowires have been proposed in literature. Among these proposed mechanisms is the thought that copper nanowires sprout and grow from spherical seeds with the concentration of (EDA) being a critical factor for anisotropic growth [30]. This seems to agree with the observations we made regarding the growth of polyaniline fibers/rods/nanotubes were at certain molar ratios more fibers are seen than spheres or elongated structures are seen stemming from spherical structures. Another argument regarding the growth process of copper nanowires and nanotubes is that, in solution the process is driven by screw dislocations [31] [32]. It is believed that by tuning the concentration of the complexing ligands $\mathrm{OH}^{-}$and EDA, low supersaturation condition of this redox reaction reaction system is created to favor dislocation 

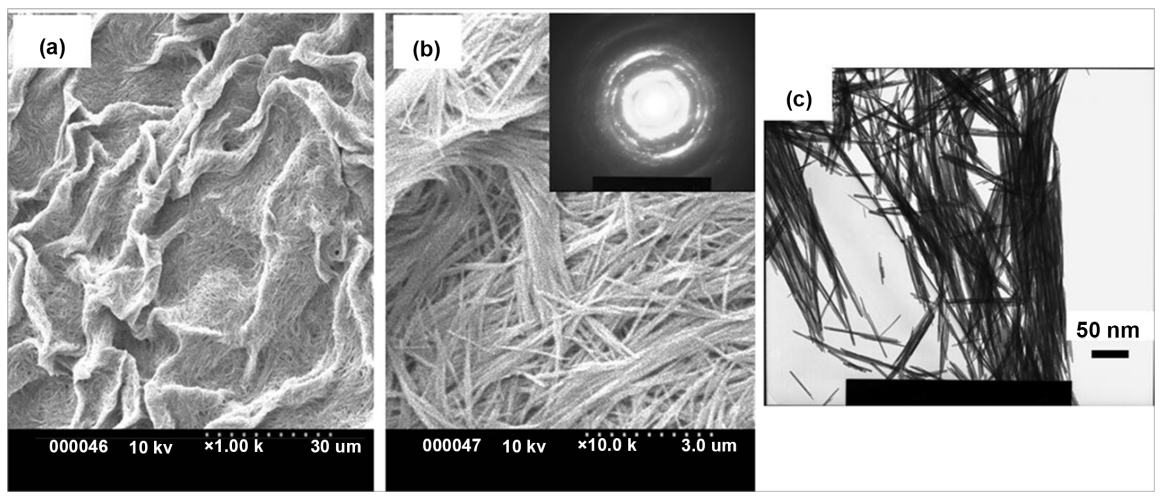

Figure 11. SEM images (a), (b) and TEM image (c), of copper(II) hydroxide nanowires. The insert is the electron diffraction image of the copper(II) hydroxide nanowires.
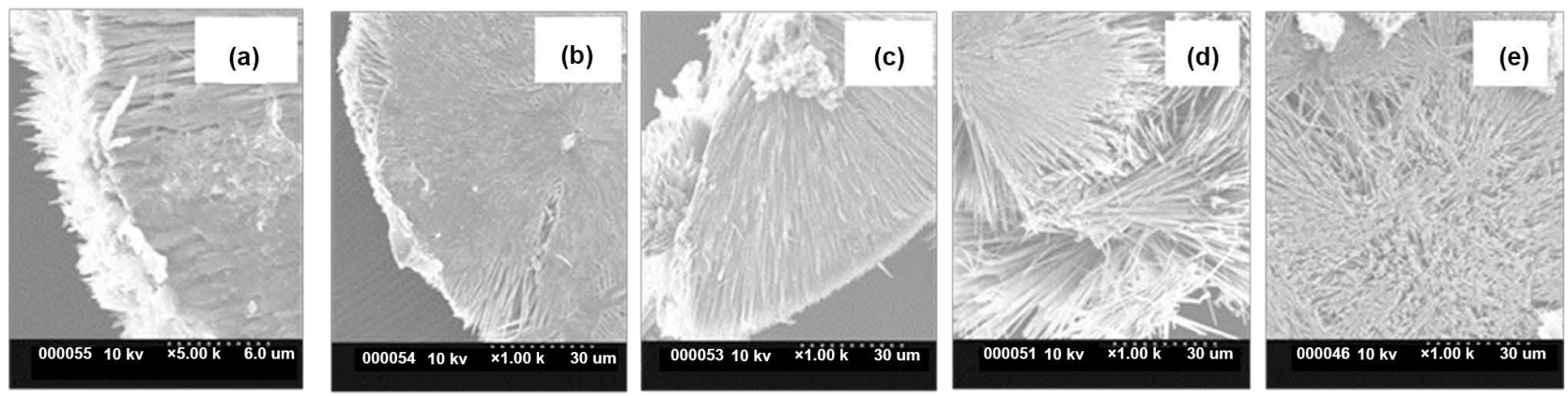

Figure 12. SEM images (a)-(e) of copper(II) hydroxide nanoribbons.

driven crystal growth, which enables a more effective copper nanowire growth under milder $\mathrm{pH}$ environment of approximately $\mathrm{pH} 12$.

It has been proposed also that $\mathrm{Cu}(\mathrm{OH})_{2}$ nanoribbons were formed by solution-phase coordination self-assembly at a relatively high $\left[\mathrm{Cu}\left(\mathrm{NH}_{3}\right) \mathrm{n}\right]^{2+}$ concentration, whereas $\mathrm{Cu}(\mathrm{OH})_{2}$ nanowires were formed by oriented attachment coupled with coordination self-assembly through a solid-solution-solid process whereby a relatively low $\left[\mathrm{Cu}\left(\mathrm{NH}_{3}\right) \mathrm{n}\right]^{2+}$ concentration was retained. The electron diffraction (ED) pattern corresponding to a bundle of $\mathrm{Cu}(\mathrm{OH})_{2}$ nanowires shows some diffusive nature which point to the orthorhombic structure of $\mathrm{Cu}(\mathrm{OH})_{2}$. This suggests that the orientation of the crystallines is not random but coordinated with the [100] direction being the preferential growth direction of the polycrystalline nanowires.

\subsection{Applications}

Compared with bulk conducting polymers, conducting polymer nanostructures are expected to display improved performance in technological applications [33]. High electrical conductivity, large specific area, short path length for the transport of ions, improved cycle life due to better accommodation caused by electrochemical reaction, mixed conductive mechanism of both electronic and ionic conductivity which lowers the interfacial impedance between electrodes and electrolyte and light weight and large ratio of specific discharge power to 
weight. All these properties lend conducting polymer nanostructures to enhance device performance in application areas such transistors, sensors, memories, actuators/artificial muscles, supercapacitors and lithium ion batteries. A more recent use of polyaniline nanofibers is in their use as fillers materials that can be blended with inherently insulating polymers to form conducting polymer nanocomposites. Quite often, carbon nanotubes, carbon fibers and other more expensive materials have been used as fillers [34] [35].

Cuprous oxide $\left(\mathrm{Cu}_{2} \mathrm{O}\right)$ and cupric oxide $(\mathrm{CuO})$ are the two natural oxide of copper [36]. They are both semiconductors with band gaps of $2.0 \mathrm{eV}$ and $1.2 \mathrm{eV}$ respectively. These narrow band gaps make them ideal for applications in photovoltaic devices such as solar cells and devices that use photolysis of water to obtain hydrogen, catalysts and sensors. At the nanoscale, copper oxide in the form of nanowires is even more desirable due to increased surface area which leads to higher absorption of photons in photovoltaic devices and consequently higher efficiencies. The availability of large surface areas translates into higher probability of species adsorbing on the surface which leads to better response in sensors.

Copper nanowires can be incorporated into polymer matrices in suitable concentrations resulting in the formation of nanocomposites that are conducting. These copper nanowire loaded nanocomposites can be used as thermal interface materials (TIMs) or for electromagnetic interference shielding (EMI) and electrostatics dissipative (ESD) [37]-[56].

\section{Conclusion}

Salicylic acid doped polyaniline nanofibers were synthesized without the use of any template. The nanostructures were found by SEM to be solid and running parallel to each other only at specific ratios of oxidant to monomer. Related experiments involving other dopant to polyaniline including camphorsulfonic acid and para-toluenesulfonic acid showed both nanorods and nanotubes. The morphology was found to be critically dependent on the oxidant/monomer ratios. In addition conductivity measurements show that the nanorod structures had better conductivity than the spherical nanostructures. To show that the template-free formation of nanofibers is not limited to conducting polymers, we successfully synthesized copper as well as copper(II) hydroxide nanowires using a similar template-free method. The conductivity was found to be 2 - 3 orders of magnitude higher relative to bulk.

\section{Acknowledgements}

We are grateful for the financial support that was provided by the Research Foundation of New York at Binghamton University. We also want to express our thanks for the unlimited access that we enjoyed to the Advanced Analytical and Diagnostic Laboratory in the Innovative Technology Complex (ITC) at Binghamton University, where we were able to use advanced equipment to characterize our materials. 


\section{References}

[1] Tran, H.D., Li, D. and Kaner, R.B. (2009) One-Dimensional Conducting Polymer Nanostructures: Bulk Synthesis and Applications. Advanced Materials, 21, 1487-1499. https://doi.org/10.1002/adma.200802289

[2] Wan, M., Liu, J., Qiu, H., Li, J. and Li, S. (2001) Template-Free Synthesized Microtubules of Conducting Polymers. Synthetic Metals, 119, 71-72.

https://doi.org/10.1016/S0379-6779(00)01400-4

[3] Wan, M. (2008) Thermal and Electrical Transport in Ultralow Density Single-Walled Carbon Nanotube Networks. Advanced Materials, 20, 2926-2932. https://doi.org/10.1002/adma.200800466

[4] Lou, X.W. (David), Archer, L.A. and Yang, Z. (2008) Hollow Micro-/Nanostructures: Synthesis and Applications. Advanced Materials, 20, 3987-4019.

https://doi.org/10.1002/adma.200800854

[5] Israelachvili, J.N., Mitchell, D.J. and Ninham, B.W. (1976) Theory of Self-Assembly of Hydrocar Bon Amphiphiles into Micelles and Bilayers. Journal of the Chemical Society, Faraday Transactions 2: Molecular and Chemical Physics, 72, 1525-1568. https://doi.org/10.1039/f29767201525

[6] Zhao, Y. and Jiang, L. (2009) Hollow Micro/Nanomaterials with Multilevel Interior Structures. Advanced Materials, 21, 3621-3638. https://doi.org/10.1002/adma.200803645

[7] Wei, Z., Zhang, Z. and Wan, M. (2002) Formation Mechanism of Self-Assembled Polyaniline Micro/Nanotubes. Langmuir, 18, 917-921.

https://doi.org/10.1021/la0155799

[8] Aleshin, A.N. (2006) Polymer Nanofibers and Nanotubes: Charge Transport and Device Applications. Advanced Materials, 18, 17-27. https://doi.org/10.1002/adma.200500928

[9] Kim, S.J., Lee, N.R, Yi, B. and Kim, S. (2006) Synthesis and Characterization of Polymeric Acid-Doped Polyaniline Interpenetrating Polymer Networks. Journal of Macromolecular Science, Part A: Pure and Applied Chemistry, 43, 497-505. https://doi.org/10.1080/10601320600575165

[10] Groenendaal, B.L., Jonas, F., Freitag, D., Pielartzik, H. and Reynolds, J.R. (2000) Poly(3,4-ethylenedioxythiophene) and Its Derivatives: Past, Present, and Future. Advanced Materials, 12, 481-494. https://doi.org/10.1002/(SICI)1521-4095(200004)12:7<481::AID-ADMA481>3.0.C O;2-C

[11] Ding, H., Wan, M. and Wei, Y. (2007) Controlling the Diameter of Polyaniline Nanofibers by Adjusting the Oxidant Redox Potential. Advanced Materials, 19, 465-469. https://doi.org/10.1002/adma.200600831

[12] Rahman, A. and Sanyal, M.K. (2007) Novel Switching Transition of Resistance Observed in Conducting Polymer Nanowires. Advanced Materials, 19, 3956-3960. https://doi.org/10.1002/adma.200700753

[13] Nechtschein, M., Genoud, F., Menardo, C., Mizoguchi, K. and Villeret, B. (1989) On the Nature of the Conducting State of Polyaniline. Synthetic Metals, 29, 211-218. https://doi.org/10.1016/0379-6779(89)90298-1

[14] Zengin, B.H., Zhou, W., Jin, J., Czerw, R., Smith, D.W., Echegoyen, L., Carroll, D.L., Foulger, S.H. and Ballato, J. (2002) Carbon Nanotube Doped Polyaniline. Advanced Materials, 14, 1480-1483.

https://doi.org/10.1002/1521-4095(20021016)14:20<1480::AID-ADMA1480>3.0.CO $\underline{; 2-\mathrm{O}}$ 
[15] Bernius, M.T., Inbasekaran, M., O’Brien, J. and Wu, W. (2000) Progress with Light-Emitting Polymers. Advanced Materials, 12, 1737-1750. https://doi.org/10.1002/1521-4095(200012)12:23<1737::AID-ADMA1737>3.0.CO;2$\underline{\mathrm{N}}$

[16] Chiou, N.R. and Epstein, A.J. (2005) Polyaniline Nanofibers Prepared by Dilute Polymerization. Advanced Materials, 17, 1679-1683. https://doi.org/10.1002/adma.200401000

[17] Shown, I., Gangluy, A., Chen, L.C. and Chen, K.H. (2015) Conducting Polymer-Based Flexible Supercapacitor. Energy Science \& Engineering, 3, 2-26. https://doi.org/10.1002/ese3.50

[18] Chen, J., Chao, D., Lu, X. and Zhang, W. (2007) Novel Interfacial Polymerization for Radially Oriented Polyaniline Nanofibers. Materials Letters, 61, 1419-1423. https://doi.org/10.1016/j.matlet.2006.07.043

[19] Li, G., Wang, Z., Xie, G., Peng, H. and Zhang, Z. (2006) Synthesis of Interconnected Polyaniline Nanofibers in Catanionic Micelles. Journal of Dispersion Science and Technology, 27, 991-995. https://doi.org/10.1080/01932690600766991

[20] Zhang, L. and Wan, M. (2002) Synthesis and Characterization of Self-Assembled Polyaniline Nanotubes Doped with D-10-Camphorsulfonic Acid. Nanotechnology, 3, 750-755. https://doi.org/10.1088/0957-4484/13/6/311

[21] Lu, C., Qi, L., Yang, J., Zhang, D., Wu, N. and Ma, J. (2004) Simple Template-Free Solution Route for the Controlled Synthesis of $\mathrm{Cu}(\mathrm{OH})_{2}$ and $\mathrm{CuO}$ Nanostructures. Journal of Physical Chemistry B, 108, 17825-17831. https://doi.org/10.1021/jp046772p

[22] Chang, Y., Lye, M.L. and Zeng, H.C. (2005) Large-Scale Synthesis of High-Quality Ultralong Copper Nanowires. Langmuir, 21, 3746-3748. https://doi.org/10.1021/la050220w

[23] Xing, S., Chu, Y., Sui, X. and Wu, Z. (2005) Synthesis and Characterization of Polyaniline in CTAB/Hexanol/Water Reversed Micelle. Journal of Materials Science, 40, 215-218. https://doi.org/10.1007/s10853-005-5711-4

[24] Chiou, N., Lee, L.J. and Epstein, A.J. (2007) Self-Assembled Polyaniline Nanofibers/Nanotubes. Chemistry of Materials, 19, 3589-3591. https://doi.org/10.1021/cm070847v

[25] Lee, H. and Wang, C. (2008) Effects of Interactions among Polyaniline, Camphorsulfonic Acid and Silica on the Structure and Properties of Their Conductive Hybrids. Polymer Engineering \& Science, 48, 439-446. https://doi.org/10.1002/pen.20972

[26] Kulkarni, M.V., Viswanath, A.K., Aiyer, R.C. and Khanna, P.K. (2005) Synthesis, Characterization, and Morphology of $p$-Toluene Sulfonic Acid-Doped Polyaniline: A Material for Humidity Sensing Application. Journal of Polymer Science, Part B: Polymer Physics, 43, 2161-2169. https://doi.org/10.1002/polb.20503

[27] Neoh, K.G., Pun, M.Y., Kang, E.T. and Tan, K.L. (1995) Polyaniline Treated with Organic Acids: Doping Characteristics and Stability. Synthetic Metals, 73, 209-215. https://doi.org/10.1016/0379-6779(95)80018-2

[28] Hino, T., Namiki, T. and Kuramoto, N. (2006) Synthesis and Characterization of Novel Conducting Composites of Polyaniline Prepared in the Presence of Sodium Dodecylsulfonate and Several Water-Soluble Polymers. Synthetic Metals, 156, 1327-1332. https://doi.org/10.1016/j.synthmet.2006.10.001

[29] Konyushenko, E.N., Stejskal, J., Sedenkova, I., Trchova, M., Sapurina, I., Prokes, J., Cieslar, M. and Prokes, J. (2006) Polyaniline Nanotubes: Conditions of Formation. 
Polymer International, 55, 31-39. https://doi.org/10.1002/pi.1899

[30] Rathmell, A.R., Bergin, S.M., Hua, Y.L., Li, Z.Y. and Wiley, B.J. (2010) The Growth Mechanism of Copper Nanowires and Their Properties in Flexible, Transparent Conducting Films. Advanced Materials, 22, 3558-3563. https://doi.org/10.1002/adma.201000775

[31] Meng, F. and Jin, S. (2012) The Solution Growth of Copper Nanowires and Nanotubes Is Driven by Screw Dislocations. Nano Letters, 12, 234-239. https://doi.org/10.1021/nl203385u

[32] Ye, E., Zhang, S.Y., Liu, S. and Han, M.Y. (2011) Disproportionation for Growing Copper Nanowires and Their Controlled Self-Assembly Facilitated by Ligand Exchange. Chemistry, A European Journal, 17, 3074-3077.

https://doi.org/10.1002/chem.201002987

[33] Pan, L., Qiu, H., Dou, C., Li, Y., Pu, L., Xu, J. and Shi, Y. (2010) Conducting Polymer Nanostructures: Template Synthesis and Applications in Energy Storage. International Journal of Molecular Sciences, 11, 2636-2657. https://doi.org/10.3390/ijms11072636

[34] Dasgupta, N.P., Sun, J., Liu, C., Brittman, S., Andrews, C.S., Lim, J., Gao, H., Yan, R. and Yang, P. (2014) 25th Anniversary Article: Semiconductor Nanowires-Synthesis, Characterization, and Applications. Advanced Materials, 26, 2137-2184. https://doi.org/10.1002/adma.201305929

[35] Byrne, M.T. and Gun'ko, Y.K. (2010) Recent Advances in Research on Carbon Nanotube-Polymer Composites. Advanced Materials, 22, 1672-1688. https://doi.org/10.1002/adma.200901545

[36] Filipič, G. and Cvelbar, U. (2012) Copper Oxide Nanowires: A Review of Growth. Nanotechnology, 23, Article ID: 194001. https://doi.org/10.1088/0957-4484/23/19/194001

[37] McCarthy, P.A., Huang, J., Yang, S.C. and Wang, H.L. (2002) Synthesis and Characterization of Water-Soluble Chiral Conducting Polymer Nanocomposites. Langmuir, 18, 259-263. https://doi.org/10.1021/la0111093

[38] Suter, J.L., Groen, D. and Coveney, P.V. (2015) Chemically Specific Multiscale Modeling of Clay-Polymer Nanocomposites Reveals Intercalation Dynamics, Tactoid Self-Assembly and Emergent Materials Properties. Advanced Materials, 27, 966-984. https://doi.org/10.1002/adma.201403361

[39] Chai, G. and Chen, Q. (2010) Characterization Study of the Thermal Conductivity of Carbon Nanotube Copper Nanocomposites. Journal of Composite Materials, 44, 2863-2873. https://doi.org/10.1177/0021998310371530

[40] Guo, Y., Zheng, M. and Chen, J. (2008) Chemical Synthesis, Characterization and Thermal Analysis of Polyaniline/Copper Composite Powder. Journal of Composite Materials, 42, 1431-1438. https://doi.org/10.1177/0021998308091998

[41] Motozuka, S., Tagaya, M., Ikoma, T., Yoshioka, T., Xu, Z. and Tanaka, J. (2012) Preparation of Copper-Graphite Composite Particles by Milling Process. Journal of Composite Materials, 46, 2829-2834. https://doi.org/10.1177/0021998311432947

[42] Li, W., Liu, L. and Shen, B. (2011) The Fabrication and Properties of Short Carbon Fiber Reinforced Copper Matrix Composites. Journal of Composite Materials, 45, 2567-2571. https://doi.org/10.1177/0021998311401108

[43] Kaman, M.O., Solmaz, M.Y. and Turan, K. (2010) Effects of Ductile Fiber Size on the Fracture Toughness of Copper/PolyesterComposites. Journal of Composite Materials, 44, 3151-3164. https://doi.org/10.1177/0021998310371540 
[44] Abdolahi, A., Hamzah, E., Ibrahim, Z. and Hashim, S. (2011) Graphene-Based Polymer Nanocomposites: Synthesis and Characterization of High-Quality Polyaniline Nanofibers. High Performance Polymers, 25, 236-242. https://doi.org/10.1177/0954008312461926

[45] Potts, R.J., Dreyer, R.D., Bielawski, W.C. and Ruoff, S.R. (2011) Graphene-Based Polymer Nanocomposites. Polymer, 52, 5-25. https://doi.org/10.1016/j.polymer.2010.11.042

[46] PapageorgiouIan, G.D., Kinloch, A.I. and Young, R.J. (2015) Graphene/Elastomer Nanocomposites. Carbon, 95, 460-484. https://doi.org/10.1016/j.carbon.2015.08.055

[47] Abdolahi, A., Hamzah, E., Ibrahim, Z. and Hashim, S. (2013) Synthesis and Characterization of High-Quality Polyaniline Nanofibers. High Performance Polymers, 25, 236-242. https://doi.org/10.1177/0954008312461926

[48] Baker, O.C., Huang, X., Nelson, W. and Kaner, B.R. (2017) Polyaniline Nanofibers: Broadening Applications for Conducting Polymers. Chemical Society Reviews, 46, 1510-1525. https://doi.org/10.1039/C6CS00555A

[49] Mohamad, S.F., Zaid, H.M.M., Abdullah, J., Zawawi, M.R., Lim, N.H., Sulaiman, Y. and Rahman, A.M. (2017) Synthesis and Characterization of Polyaniline/Graphene Composite Nanofiber and Its Application as an Electrochemical DNA Biosensor for the Detection of Mycobacterium tuberculosis. Sensors, 17, E2789.

https://doi.org/10.3390/s17122789

[50] Singh, P.D., Ojha, K.A. and Srivastava, N.O. (2009) Synthesis of Different $\mathrm{Cu}(\mathrm{OH})_{2}$ and $\mathrm{CuO}$ (Nanowires, Rectangles, Seed-, Belt-, and Sheetlike) Nanostructures by Simple Wet Chemical Route. Journal of Physical Chemistry C, 113, 3409-3418. https://doi.org/10.1021/jp804832g

[51] Yu, J., Zhou, T. and Pang, Z. (2016) Flame Retardancy and Conductive Properties of Polyester Fabrics Coated with Polyaniline. Textile Research Journal, 86, 1171-1179. https://doi.org/10.1177/0040517515606360

[52] Wu, K., Yu, J. and Jiang, X. (2017) Multi-Walled Carbon Nanotubes Modified by Polyaniline for the Removal of Alizarin Yellow R from Aqueous Solutions. Adsorption Science \& Technology, 1-17.

[53] Pierini, F., Lanzi, M., Nakielski, P. and Kowalewski, A.T. (2017) Electrospun Polyaniline-Based Composite Nanofibers: Tuning the Electrical Conductivity by Tailoring the Structure of Thiol-Pro Tected Metal Nanoparticles. Journal of Nanomaterials, 2017, Article ID: 6142140.

[54] Liu, P., Zhu, Y., Torres, J., Lee H.S. and Yun, M. (2017) Facile and Template-Free Method toward Chemical Synthesis of Polyaniline Film/Nanotube Structures. Journal of Polymer Science, Part A: Polymer Chemistry, 55, 3973-3979. https://doi.org/10.1002/pola.28749

[55] Ye, S., Stewart, E.I., Chen, Z., Li, B., Rathmell, R.A. and Wiley, J.B. (2016) How Copper Nanowires Grow and How to Control Their Properties. Accounts of Chemical Research, 49, 442-451. https://doi.org/10.1021/acs.accounts.5b00506

[56] da Silva, G.M.A., Rodrigues, S.T., Parussulo, L.A.A., Candido, E.G., Geonmonond, S.R., Brito, F.H., Toma, E.H. and Camargo, H.C.P. (2017) Controlled Synthesis of Nanomaterials at the Undergraduate Laboratory: $\mathrm{Cu}(\mathrm{OH})_{2}$ and $\mathrm{CuO}$ Nanowires. Journal of Chemical Education, 94, 743-750.

https://doi.org/10.1021/acs.jchemed.6b00185 